\title{
HIV/AIDS TESTING IN BOTSWANA: A CASE STUDY OF SELEBI PHIKWE
}

\section{Kwaku Osei-Hwedie}

\section{INTRODUCTION}

HIV/AIDS is one of the most critical current global socio-economic problems. Apparently, there is no country that has not suffered the epidemic. It is a disease that has crippled many governments' budgets and disrupted medical research, since no cure has been found. Thus it has caused a lot of strain, especially, in the Third World, where poverty is a major problem. This is mainly because of lack of resources and facilities, poor general health and long periods of social unrest and economic disruption (Monkge,, 1999).

In 2005 it was estimated that 270,000 people in Botswana, with a total population of 1.7 million, were HIV positive www.globalhealthreporting.org (2007). However, in 2004 official government sources put the incidence rate at 17 percent, a significant reduction from the estimated 38 percent in 2003 (National Aids Coordinating Agency (NACA)). Despite the high incidence rate, only a few thousand actually know their status (UNAIDS, 2006). Unfortunately, many people are now so frightened of HIV that they prefer to remain ignorant rather than test positive and be stigmatised. However, the diagnosis "HIV positive" no longer has to mean imminent death. By running away from being tested until they are seriously ill, many people with HIV unknowingly pass a death sentence on themselves and sometimes on others too.

Botswana is one of the countries hardest hit by the HIV/AIDS epidemic (Botswana Institute of Development Policy Analysis (BIDPA) 2000). The government recognises the impact of the epidemic and therefore offers free antiretroviral (ARV) drugs to HIV-positive citizens (http://en.wikipedia.org/wiki/Botswana2007). Most Batswana have not tested for HIV and only about 42000 were taking ARV drugs (52\% of the 75000 estimated to be in need of ARV as of December 2004) (WHO/UNAIDS, 2005), although this figure was expected to rise to about 55 000. It was hoped that by the end of 2005 at least 3 out of every 5 people who needed ARV drugs would be covered by the ARV programme. However, access to all ARV drugs is based on knowing one's HIV status, which depends on testing by appropriate health institutions. The paper therefore discusses the factors which prevent people from getting tested for HIV, the importance of knowing one's status, and measures that may attract people to get tested.

\section{RESEARCH METHODOLOGY}

This study was conducted in December 2004 in four locations in Selebi Phikwe (Bamangwato Concession Limited (BCL), Distance, Ikageleng and Botshabelo), a town in the Central District of Botswana about 400 kilometres from Gaborone, the capital,. It is a mining town with a total population of an estimated 49849 people, of whom 24859 are aged between 20 and 49 years (Central Statistics Office, 2001). Thirty-four respondents between the ages of 21 and 49 were interviewed using purposive/convenience sampling. Whoever was available was interviewed and homes were randomly selected. Thus 5 respondents were interviewed in the areas of Ikageleng; nine in Botshabelo; ten in BCL; and ten in Distance.

The study was exploratory in nature and investigated the reasons which deter people from being tested, through both qualitative and quantitative methods of data collection. An exploratory design was used for this study, because there is little known in relation to why people do not test for the HI virus. Neuman (2003) adds that exploratory designs seek to enable the researcher to become familiar with people's views (on testing, in this case). It also helps in 
developing a well-grounded mental picture of the existing situation (what is occurring) and provides a sense of direction for future research. Face-to-face interviews were used to gather information about reasons why people do not test and to see if they were familiar with services in their communities.

Many medical conditions require laboratory tests on samples of blood, urine, saliva or tissue to identify infections or health problems. Tests may be carried out on healthy individuals to detect hidden problems or on people who are already sick. Although HIV is found in various body fluids, tests are generally done on blood, because the virus is most concentrated in blood. The most widely used tests for HIV detect these antibodies, not the virus itself. According to Jackson (2002), these tests should really be called "HIV antibody tests", never "Aids tests", as they only reveal underlying HIV infection and not the progression to AIDS.

Everywhere, people are reluctant to be tested for fear of censure (Gilbert, 2000). This sets in motion a cycle of guilt, shame and denial which impedes both treatment and prevention. For example, more than half of a group of HIV-positive women in Kenya hid the news from their partners, because they feared they would be beaten or abandoned. In Swaziland prominent politicians proposed that "people with Aids" should be forced to wear identification badges and be herded into special segregated areas where they will not be able to contaminate "normal people". The stigma surrounding Aids does not only deter people from being tested, but turns them away from seeking care and treatment (UNAIDS Press Release 2003). Some people choose not to test because they have concerns about the confidentiality of the test results, and fear possible discrimination in such areas as insurance and employment. Individuals who fear rejection or discrimination based on their HIV status may delay getting tested (UNAIDS Press Release, 2003).

\section{POPULATION GROUPS THAT NEED TESTING}

All people who are sexually active and with multiple partners should know whether they are infected with HIV. These include those attending sexually transmitted disease and drug treatment clinics; women of child-bearing age; tuberculosis (TB) patients; all pregnant women; and all people who think they have been exposed to HIV. If people know their status, they will be able to take the precautions necessary to protect others from becoming infected. Women who are HIV positive and pregnant can receive appropriate and timely medical interventions, both for their own health and to reduce the risk of mother-to-infant HIV transmission in the uterus through delivery or breast feeding (www.amfar.org, undated).

HIV testing plays a critical role in both treatment and prevention. Testing can identify HIVinfected individuals who could benefit from treatment and counselling. Also it can help them to remain healthy and reduce the risk of transmitting the virus to others. Testing can identify uninfected people who are at risk, and who may be involved in unsafe sex or needle sharing, and would benefit from risk-reduction counselling. Test results and statistics can also facilitate the appropriate allocation of public health resources (www.amfar.org undated).

Reducing HIV infections requires permanent behaviour change along with comprehensive and sustained rollouts of anti-retroviral therapy (ARVs) and other medication. Sustainability requires continuous investment of enormous resources to ensure that everyone who needs these gets them. However, provision of ARVs will in itself only stabilise the number of people living with HIV and not prevent new infections. Therefore, it is necessary to combine anti-retroviral therapy with safer sex practices and other behavioural change strategies. 


\section{ANTIRETROVIRAL DRUGS}

The national ARV therapy was given the name MASA, the Setswana term for 'dawn'. The first ARV drugs were provided in Gaborone in January 2002. The African Comprehensive AIDS Partnership (ACHAP) is one of the partners in the programme providing both financial and technical assistance. As of 2005, the MASA programme had about 42000 patients on ARV therapy and the provision of treatment had reduced the deaths related to HIV/AIDS by about 10\%. By December 2004 there were about 35 operational ARV sites in Botswana (Botswana Government, 2004).

By 2004 MASA was enrolling new patients at a rate of about 1000 per month. Treatment provision has been built around a 'site' model. A MASA site consists of a treatment initiation centre (referral, district or primary hospital), supported by four screening satellite clinics. At the screening clinics patients are assessed to determine eligibility for treatment in the MASA programme. Eligibility is defined as being HIV positive with either an AIDS defining illness, CD4 of 200 or less, or being a child (Botswana Government, 2004).

The MASA antiretroviral therapy programme of Botswana defines ARV therapy as a combination of medicines that are taken by an HIV-positive person to reduce the amount of HIV in the body. It is the main type of medication for HIV/AIDS. Although it is not a cure, it can slow down the progression of the illness. The therapy always consists of two or more different medications that have to be taken every day for the rest of the patient's life. It is given to people who are HIV positive, but who do not yet have full-blown Aids, and to people who have developed Aids. However, not all those who are HIV positive need the therapy, as it is only appropriate for those whose immune systems have been seriously weakened by the HI virus (Ministry of Health, 2002a).

ARV therapy may reduce the amount of virus to the point where it can no longer be found in a person's blood. However, it cannot completely remove it. It has been realised that it slows down the growth of HIV, allowing people to become stronger and live a healthier and more productive life. This means that they will suffer from fewer opportunistic diseases and will have the opportunity of staying alive longer. For now, doctors believe that ARV therapy can allow most people with HIV/Aids to live up to ten years longer, depending on how far advanced the HIV infection had been when the therapy was started (Ross-Flanigan, 2001).

The introduction of ARV therapy is redefining Botswana's health care systems and forcing health policy changes. So far most of these changes seem to be positive, because ARV therapy has led to unprecedented cooperation between different sectors, specialisations and disciplines. This cooperation has resulted because proper patient care demands a holistic approach to treating patients as they move between their homes, communities, workplaces and health facilities. Antiretroviral therapy has also served as the central point for alignment and cooperation across numerous sectors and ministries. For example, the Ministry of Finance and the Ministry of Works (responsible for all public infrastructure) have become part of an extended health sector implementation team with defined roles and responsibilities that include actual involvement at the programmatic level (Botswana Government, 2004).

Strategies have been adopted in order to improve adherence to, and success of, ARV therapy. These include taking medicines at the right time and in the right way; not sharing ARVs medicine with anyone; working closely with the health care team to understand how to take the medication; informing the health care team and traditional or spiritual healer about all the medicines and herbs being taken; making sure that condoms are used at all times during sex to 
prevent the virus from being passed on and to avoid being re-infected; eating the appropriate foods to make the body stronger, including energy-giving and body-building foods; and reducing alcohol intake and smoking, since alcohol damages the body and makes it weaker (Ministry of Health, 2002b)

\section{BARRIERS TO TESTING}

Simooya (2000) discusses barriers to testing and the vulnerability of women to HIV/AIDS. He concludes that there is a widespread resistance to HIV testing in most African countries. This is closely related to the denial of HIV/Aids in general, and to people who are uncomfortable in discussing HIV/Aids not opening up to an HIV test. He had several clients who showed clinical signs of HIV infection and who had the ability to buy ARVs, but were not willing to take the test. There are a number of factors which contribute to late diagnosis of HIV amongst people in Africa. These include stigmatisation surrounding HIV; limited awareness of services that can offer support; and concerns and doubts about the efficiency of HIV testing. Many people maintain that HIV does not exist despite the fact that they live in areas of high prevalence (Rugalema, 2000).

\section{FINDINGS AND DISCUSSION \\ Bio-data}

Of the 34 respondents, $20(58.8 \%)$ were aged between 21 and 30 years; 7 (20.6\%) were between 31 and 40 and 7 (20.6\%), were between 41 and 49. The data show that the majority of the respondents were still young adults in their reproductive years. This is not unusual, given the fact that Selebi Phikwe is an industrial (mining) town and many residents are there for work purposes, either working or searching for jobs. It is possible that those who retire go back to their home villages.

Fifteen $(44.1 \%)$ of the respondents were males and $19(55.9 \%)$ females. This may reflect the fact that more females were found at home during the time the research was conducted. There is a high rate of unemployment among women in Botswana, leading to their spending much time at home. The data indicate that $18(52.9 \%)$ of the respondents were single, $8(23.5 \%)$ were married, $5(14.7 \%)$ were divorced and $3(8.8 \%)$ were widowed. This shows that the majority of respondents were single. Those divorced and widowed were also technically single, as they were no longer with their partner as a result of death or marriage breakdown. With respect to widows, this may be an indication that many people are losing their spouses to death because of factors that include HIV infection. This is significant in that it demonstrates the high death rate in Batswana resulting from the HIV/Aids epidemic and the breakdown of the normal family system.

The majority of respondents (12 or $35.3 \%$ ) had one child; closely followed by those without children (10 or $29.4 \%$ ); those who had 2 children each (6 or 17.6\%); 3 (8.8\%) respondents had 3 children each and lastly $2(17.6 \%)$ respondents had 6 children each. This confirms that Botswana is a society with a large dependent population. This again exacerbates the orphan problem, given the number of adult deaths and the many children left behind. With respect to education, $6(17.6 \%)$ of the respondents completed primary education; $12(35.3 \%)$ had gone up to junior secondary; 7 (20.6\%) had attained a senior secondary certificate; and $9(26.5 \%)$ had tertiary education. The data show that the majority of the respondents were well educated, with $82.4 \%$ having reached educational levels above primary school. All the respondents had some 
education and this may reflect how well educational policies are working in the country with respect to opportunities and school attendance.

The fact that a majority of the population have a reasonable level of education plays a very important role in the HIV/Aids educational programmes, as people are supposed to be able to read and understand the information that is given to them. People who are able to read and write are also able to listen to the radio and use different types of media, including television, newspapers and billboards, to access the information provided. This also means that they can broaden their knowledge on HIV/Aids through the messages, and understand and interpret the message conveyed correctly.

To some extent, it is evident that the educational system of the country plays a significant role in curbing the HIV epidemic. HIV is widely distributed in Selebi Phikwe, because of the movement of people in and out of the town. This is a commercial centre where people who are educated come to seek greener pastures and there is high population mobility. Most of these people do not know their status and end up having sex with those who are called the "town keepers" (people who live permanently in Selebi Phikwe and are less likely to have lived anywhere else), and who are also likely to have had many sexual partners without knowing their HIV status.

With respect to gender and marital status, more females, 11(61.1\%) were single compared to the $7(38.8 \%)$ men who were single. There is higher infection rate among women than in men all over the country and the world. This might be because a lot of them are single and hence may be involved with multiple partners. Also, generally, women are more vulnerable and socially less able to negotiate for safer sex. Nineteen $(55.9 \%)$ of the respondents were females who were at home. Most of them were unemployed and had a great deal of free time. When people have nothing to do, sex may become one of their pastime activities. Two $(66.6 \%)$ men were widowed compared to $1(33.3 \%)$ woman who was widowed.

\section{SOCIO-ECONOMIC PROFILE}

Botswana has a youthful population, a large proportion of which is of working age. The age of the respondents corresponds with that required by an industrial-mining town and represented the many people either working or looking for jobs in Selebi Phikwe. It is possible that many of those who retire move back to their original villages, since after retirement it is difficult to find another job in Selebi Phikwe or continue staying in government or mine houses. The presence of a large number of working-age males and females also suggests that a large proportion of the population is sexually active. This has serious implications for the prevention and control of HIV/Aids and care for the infected. There is a high chance that many of these may engage in risky sexual behaviour. The nature of the population under study, for example, was characterised as having several dependants. This underscored the high level of sexual activity, as $71 \%$ of the respondents had children and the possibility of many of them becoming orphans as a result of HIV/Aids-related deaths remained high.

The data demonstrated high levels of education and intellectual capacity of the respondents, Given this fact, it is baffling that Selebi Phikwe has one of the highest HIV/Aids infection rates in Botswana. It could be assumed, based on this study, that at least $50 \%$ of all those infected may have junior secondary education and higher. This therefore brings into question the impact of formal education in the fight against HIV/Aids. The fact that the high numbers of those infected were well educated may mean that infection was not solely due to ignorance, lack of knowledge, or abject poverty. The causes may lie elsewhere. For example, because the 
population is highly educated, urbanised and relatively mobile, this may influence their attitudes and behaviours towards sexual relationships. Because of the high level of mobility, there may be a greater chance of casual sexual relationships, with "no strings attached". In this case the availability of educational materials on television, newspapers and billboards, and the ability to access these may not, in itself, change people's attitudes and beliefs about whether they are at risk or not.

Again part of the problem may be found in the fact that, according to the data, many respondents, especially women, were single. This raises the probability of non-stable sexual relationships. This is reinforced by the high rate of female unemployment, which may force them to engage in risky sexual relationships. Again, it is evident that more females are dying of Aids-related illnesses, which reflects the high infection rate among women.

\section{NON-VOLUNTARY TESTING}

Despite the information that is continuously being circulated to people on the factors that lead to HIV infection, and the need for them to know their status, many are still reluctant to test. From the data it appeared that there was a high level of reluctance amongst the population to test voluntarily. In relation to testing, there was a pattern that shows that people who tested did so unwillingly. For example, most of the respondents who had tested did so because their partners had tested. If one of the partners tested negative, then he/she would like to know the status of the other in the interest of a sound relationship. Likewise, if the partner was positive, he/she might not want to be in a relationship with the other without knowing his/her status. Therefore, for both of them to be in that relationship, the other was forced to test. If people do not engage in risky behaviour, then there was no need to test. However, if they were engaged in unprotected sex, then it "nagged" them to test as they would possibly want to make sure that they were not infected.

Some people who test were not prepared for the results. The data show that $28.6 \%$ of the respondents who went to test did not go back for the results. If one went to test involuntarily, then it became very hard to go back for the test results. This is usually due to the possibility that he/she was not emotionally prepared for the outcome. This has serious implications for HIV education and testing programmes. Part of the HIV/Aids message extols the virtue of being HIV negative. In view of this, those who are not sexually active are encouraged to remain so. Also, the emphasis is placed on universal testing for all those who are sexually active and must know their status. However, universal testing is not yet an official policy in Botswana and routine testing has also not yielded the desired results, as people do not present themselves for the tests and, in many instances, for the results.

\section{REASONS PEOPLE DO NOT TEST}

One of the objectives of the study was to identify why people did not test for HIV voluntarily. It was found the respondents generally knew what an HIV test is since 19 (55.85\%) respondents knew about it. They understood it to involve testing for the presence of the virus and knowing one's status. They mentioned hospitals, clinics, the Tebelopele Counselling Centre (a Setswana word meaning 'vision') and private practitioners as places that offer testing facilities. There was high awareness of people who had tested in the family. People went for the test for several reasons, including being pregnant; partner having tested; encouragement from partners; scholarship requirements; and having been involved in risky sexual behaviours. Most of the respondents ( 21 or $61.8 \%$ ), indicated that they had tested, but only $15(71.4 \%)$ of those 
who had tested actually knew their status. This suggests that people use the facilities for testing, but do not always return for their results.

Twenty-nine $(85.2 \%)$ of the respondents did not see themselves as being at risk of contracting HIV, attributing this to positive living and taking care of themselves since their last HIV test. Only one respondent indicated that he might be at risk because he had had unprotected sex more than once. Respondents who had been involved in high-risk situations had not considered going for testing after the event, except for a few who tested because the condom had broken during the act of sex. Other reasons for testing were that they did not know the status of their partner and having unprotected sex with a friend after both of them had been drinking alcohol. Reasons for not testing included: not being ready to take the test; being afraid of going for the tests; trusting all the people with whom they had sexual contact; and not seeing the need for the test.

Thirteen (65\%) of the respondents who had subsequently tested were initially afraid to do so as they feared the outcome of the results. Those who were afraid said it was because their scholarship depended on the results of the tests, they were not ready for positive results, they had made many mistakes in life, and the outcome of the test would determine their future. Generally, the respondents did not know what to expect. Respondents who were not afraid cited reasons such as being ready for any results, having confidence in their sexual history, and that their partners had already tested and were negative.

Data indicated that respondents did not test because of ignorance; a mistaken belief that HIV/Aids does not exist; belief in traditional healers and seeking help from them when sick instead of going to have a test; long queues at voluntary testing centres and hospitals; fear of being positive and adjusting to the unknown; a cultural belief that Aids is still caused by witchcraft; and their sexual history. Furthermore, they did not test because of fear of the negative treatment they may get if others knew their HIV-positive status; and the belief that only those who are sick must test.

\section{KNOWLEDGE AND USE OF COUNSELLING SERVICES}

Twenty-two (64.7\%) respondents knew about counselling and defined it as talking to someone who has been trained for that job, learning about testing, talking to someone about problems and getting advice. Thirty (88.2\%) respondents did not know any counsellors. Only 4 (11.8\%) knew counsellors as they were their relatives, friends and fiancées. They had also met some counsellors through workshops, meetings and village committees.

Twenty-one $(61.8 \%)$ respondents had gone for counselling by attending up to three sessions. Here they discussed the risks of unprotected sex, the ways of accepting a member of the family or a friend who is positive, past sexual experiences, the need for trusting and being involved with one partner, and how to take care of themselves if they were HIV positive. Eleven (52.3\%) respondents felt that the sessions were useful and prepared them for the period of waiting for the results; they were able to learn about the risks involved in unprotected sex and reflect on their decision to test. Four (30.7\%) respondents did not wish to know about counselling.

\section{GAPS IN SERVICES}

People who do not return for their results show some of the weaknesses/gaps in the test and counselling programmes. The pre-test counselling is supposed to help those who test to allay their fears and enable them chart their way forward with respect to positive living. Thus, if they do not return for the results, it may mean that the counselling has not enabled them to resolve 
outstanding issues and internal conflicts, and that their conscience may still be bothering them. They may also be afraid of the consequences of the result for their relationship with their significant others, and if the result is positive, the negative reactions and stigma that may result. A large number of respondents who were also afraid to test means more efforts should be put into education and counselling programmes.

The data show that the $30.7 \%$ of the respondents who did not know about counselling services were not eager to learn about them. This may reflect an entrenched attitude of "I don't care" of some segments of the population. This poses serious challenges to the HIV/Aids campaign, given the high incidence of infections, high rates of Aids-related deaths, and the large numbers of those affected. These make it important that people should be familiar with available services, and be willing to access them when necessary. However, sometimes irrespective of the knowledge and services provided, some people may not be wiling to access them on their own to improve and sustain their own welfare. It is, therefore, necessary to identify and target such people for specialised programmes.

\section{FAMILIARITY WITH SERVICES}

In general, the fact that counselling centres are established in all communities does not mean that people know what the facilities are for, or the services that the counsellors can provide for them. Lack of knowledge about counsellors or what counsellors do is a worrying situation. This underlines the importance of ensuring that people know of the counselling facility and the staff in their communities. The few respondents who knew of counsellors did so because they were their relatives or friends. This may also demonstrate that counsellors and counselling facilities are not popular and, therefore, not well patronised in the communities. The only other way of knowing about counsellors was through workshops. The fact that not many ordinary people attend workshops and seminars indicates that other ways of making counselling and counsellors familiar must be found.

\section{ARV TREATMENT}

Most respondents knew about ARV, indicating that it was medication given to people who are HIV positive, pills to cure Aids and medication to control the growth of the virus. Respondents also stated that ARVs kept people who are infected alive; made them better; increased lifespan; helped to restore the immune system; and kept the virus "constant", i.e. prevent its multiplication. These responses reflect a clear understanding of the purpose of ARVs as part of the government's efforts to help those who are HIV positive. Thus, the respondents' understanding of ARVs was consistent with official perceptions of the nature and role of antiretroviral treatment.

Fifteen $(53.6 \%)$ of the respondents believed that not everyone who is HIV positive should have access to ARV medication. These respondents strongly believed that people should have been responsible enough not to become infected in the first place. They noted that ARV was expensive and increased the workload of health practitioners. Respondents who believed that all HIV-positive people should be on treatment supported their views by saying that the patients may be "cured" and may lead a longer life. Thus, it may help them to be strong if they were put on treatment immediately.

\section{SUBSTANCE USE AND HIV/AIDS}

There is a link between alcohol consumption and risky sexual behaviour. It is often emphasised that drinking alcohol lowers people's inhibitions about risky behaviour and therefore they are 
more at risk. In this study the data also show that alcohol contributes to the spread of HIV/Aids in the sense that some respondents' behaviour changed after a few drinks. This connection between casual or unprotected sex and alcohol and drug use is also significant, given the high level of alcohol consumption amongst all segments of the society. A large number of respondents, for example, believed that they could not be at risk. This belief may be reinforced by taking substances such as alcohol and drugs, and may lead them to have sex with strangers as well as friends whose HIV status is unknown. This connects well with the theoretical model which assumes that what people believe about their chances of getting infected usually affects the way they behave (Glanz, Rimer and Lewis, 2002). In this instance respondents' belief that they cannot be infected, combined with alcohol consumption, placed them at high risk.

\section{STIGMA ASSOCIATED WITH HIV/AIDS}

There is still a great deal of stigma attached to HIV/Aids infection and those living with the virus. Even when ARV medication was available, the majority of the respondents believed that not everybody infected should get the medication, despite the fact that it is free. This is based on their negative attitudes towards those infected based on the argument that they should not have been irresponsible in the first place. This shows that the message exhorting people not to blame those infected has to some extent fallen on deaf ears. Therefore, they felt that the infected person should not be treated with respect, compassion and affection by many people.

\section{SUSTAINABILITY OF THE ARV PROGRAMME}

In general, the ARV programme also raises questions concerning cost implication and issues of sustainability. Since those infected get the medication free, the government must find ways of sustaining the supply. This may mean that resources are diverted from other sectors of the economy. Through ARV medication, many infected people are living longer and this has implications for care. The increased lifespan of those infected means more resources may have to be invested in their care, and that care givers may have to remain on the job longer. There may also be a relationship between non-testing and provision of ARV drugs as adherence is complex and involves a strict regime. Thus, those who are not disciplined and unwilling to change their behaviour may not want to test so as not to go on ARV treatment. Therefore a facility that is supposed to help those infected may also create problems for some of the very people it is supposed to assist. However, the availability of ARVs also encouraged people to test.

\section{RECOMMENDATIONS}

It is recommended that the government, in collaboration with Tebelopele Voluntary Testing Centres, undertake targeted programmes for specific groups, and take the counselling and other services to the people, in particular their places of work and residence. This may be helped by opening more counselling and testing centres in the communities. The delivery of treatment should be such that it is accessible to people within their areas of residence where there are health posts, clinics, primary hospitals, referral clinics and mobile clinics. In addition, communities should be helped by health professionals to have open discussions such as at the kgotla (a traditional place used for meetings usually chaired by the chief or his/her designate and attended by all residents of a village to discuss various issues affecting the community) on issues of stigma and discrimination. This is to help people change their behaviour and attitudes towards those who are living with the virus, and to enable them to accept that HIV/Aids exists and affects all families and communities. It is important that more emphasis is placed on pretest counselling to better prepare those who test for the results. 


\section{CONCLUSION}

The study set out to identify and discuss the issue of why people do not go for HIV tests. Some of the reasons why people do not test include the belief that Aids does not exist. There is high involuntary testing amongst people, especially pregnant women, and those who need to meet the requirements of a particular service, such as those who need a scholarship. From the data it is evident that there are still high levels of reluctance amongst the population to test voluntarily. The study also sought to assess the importance of knowing ones status and found that people still do not view knowing their status as a priority. Rather, they see it as an action that one has to undertake only when it is absolutely necessary, such as in the course of getting married or going overseas on government sponsorships. It is believed that routine testing will lead to behaviour change and de-stigmatisation, resulting in testing becoming part of a regular health check for many people. Programmes targeted to specific population groups, as well as those that make HIV/Aids services more accessible, are critical to the fight against the epidemic.

\section{REFERENCES}

BOTSWANA GOVERNMENT. 2004. MASA update. Volume 9. Gaborone.

BOTSWANA INSTITUTE OF DEVELOPMENT POLICY ANALYSIS (BIDPA). 2000. Macro-Economic Impacts of the HIV/AIDS epidemic in Botswana. Gaborone: Ministry of Finance and Development Planning.

CENTRAL STATISTICS OFFICE. 2001. Population and housing census, national statistics table report. Gaborone: Government Printer.

GILBERT S. 2000. Ten reasons not to take an AIDS test. Available: www.virusmyth.net. [Accessed: 25/07/2004].

GLANZ K., RIMER B.K. \& LEWIS F.M. (ed) 2002. Health behaviour and education theory, research and practice. San Francisco: Jossey Bass.

JACKSON H. 2002. AIDS Africa: Continent in crisis. Avondale, Harare, Zimbabwe: SAFAIDS.

MINISTRY OF HEALTH. 2002a. MASA: Antiretroviral therapy: what you should know about ARV therapy. Gaborone: Government Printer.

MINISTRY OF HEALTH. 2002b. Clinical advisory committee on the management of HIV/AIDS; Botswana guidelines on antiretroviral treatment 2002 version. Gaborone: Government Printer.

MONKGE, M.D.C. 1999. Proceeding of the national counselling conference. Gaborone: Department of Curriculum Development and Education, Ministry of Education.

NATIONAL AIDS COORDINATING AGENCY (NACA). 2004. Botswana AIDS Impact Survey II. Gaborone: Government Printer.

NEUMAN, L.W. 2003. Social research methods: qualitative and quantitative approaches $\left(5^{\text {th }}\right.$ ed). Boston: Allyn and Bacon.

ROSS-FLANIGAN, N. 2001. Gale encyclopaedia of medicine. Available: WWw.findarticles.com. [Accessed: 15/10/2004].

RUGALEMA, G. 2000. Best practices addressing HIV/AIDS challenge. Available: http:/www.edc.org. [Accessed: 15/10/2004]. 
SIMOOYA, O. 2000. HIV testing and women's risk of infection. Available: http:/www.edc.org. [Accessed: 12/10/2004].

UNAIDS Press Release. 2003. Available: www.un.org/unaids access. [Accessed: 15/10/2004].

UNAIDS. 2006. 2004 Report on the global AIDS epidemic. Geneva: UNAIDS.

WHO/UNAIDS. 2005. Progress on global access to HIV antiretroviral therapy. An update on "3 by 5", June 2005.

www.amfar.org (undated) A practical guide to getting tested for HIV-a crucial but under used, resources in fighting AIDS. [Accessed: 14/09/2004].

www.globalhealthreporting.org 2007. HIV/AIDS in Botswana. [Accessed: 05/10/07].

Prof Kwaku Osei-Hwedie, Department of Social Work, University of Botswana, Gaborone. Botswana. 